\title{
Acoustic emission behavior of steel fibre reinforced concrete under bending
}

\section{$\operatorname{AUTHOR}(\mathrm{S})$ :}

Soulioti, D.; Barkoula, N.M.; Paipetis, A.; Matikas, T.E.; Shiotani, T.; Aggelis, D.G.

\section{CITATION:}

Soulioti, D....[et al]. Acoustic emission behavior of steel fibre reinforced concrete under bending. Construction and Building Materials 2009, 23(12): 3532-3536

\section{ISSUE DATE:}

2009-12

URL:

http://hdl.handle.net/2433/123383

\section{RIGHT:}

Copyright @ 2009 Elsevier; この論文は出版社版でありません。引用の 際には出版社版をご確認ご利用ください。; This is not the published version. Please cite only the published version. 


\title{
Acoustic emission behavior of steel fibre reinforced concrete under bending
}

\author{
D. Soulioti ${ }^{1}$, N. M. Barkoula ${ }^{1}$, A. Paipetis ${ }^{1}$, T. E. Matikas ${ }^{1}$, T. Shiotani ${ }^{2}$, D. G. Aggelis ${ }^{1 *}$ \\ ${ }^{1}$ Department of Materials Science and Engineering, University of Ioannina, \\ Ioannina 45110, Greece \\ ${ }^{2}$ Graduate School of Engineering, Kyoto University, Nishikyo-ku, Kyoto 615-8540, Japan
}

\begin{abstract}
The present paper describes the Acoustic Emission (AE) behavior of concrete under four-point bending. Steel fibres of varying content were used as reinforcement in concrete slabs and their influence on the fracture process and the acoustic activity was investigated. The total acoustic emission (AE) activity was found to be directly proportional to the fibre content. Analysis revealed that particular AE parameters change monotonically with the progress of damage and can be used for the characterization of the failure process.
\end{abstract}

Keywords: Acoustic emission, bending, concrete, fracture, steel fibres.

\section{Introduction}

Fibre reinforced cementitious materials are being increasingly employed in structural applications. Fibres prevent the brittle failure of the matrix, improving its weak tensile properties [1]. The possibility that the crack growth will be delayed by the fiber action increases with increasing fibre volume content. Consequently, the material toughness is enhanced $[2,3]$. Typically, an unreinforced concrete member fails catastrophically after the maximum load is reached. Fibres mainly improve the post-peak behavior of concrete where the multiple cracking

*Corresponding author, Tel: 003026510 98006, Fax 003026510 98054, email: daggelis@cc.uoi.gr 
acts as an energy absorbing mechanism which is totally absent in the case of unreinforced concrete. It should be noted, that the maximum load increases significantly with fibre reinforcement $[4,5]$.

In order to clarify the above mechanisms, acoustic emission (AE) monitoring has been carried out during fracture tests. The $\mathrm{AE}$ technique has been employed in numerous applications for damage characterization of concrete materials and structures [6-12]. Suitable sensors are placed on the surface in order to record the transient waves (hits) generated by the crack propagation incidents inside the material. Subsequently, the characterization and quantification of the damage level is performed via the use of appropriate AE descriptors. Further study of the transient waveforms provides in depth insight of the fracture process. The source of the AE activity is closely connected to the mode of fracture $[13,14]$. If the dominant mode is determined, it is possible to reinforce the structure using proper design or materials with increased resistance against the specific cracking mode. Additionally, the nucleation of shear cracks generally follows the propagation of tensile cracks. Therefore, the classification of cracks may lead to an early warning prior to final fracture $[8,13]$. However, the application of AE to such materials entails certain difficulties. These mainly concern the accurate interpretation of the results due to the different individual processes that contribute to the fracture of concrete. Fracture occurs due to matrix cracking and the failure of different interfaces; i.e. between cement paste and sand, aggregates and fibres. Final failure includes aggregate crushing and fibre rupture [15]. As is generally accepted, the fracture process of fibre reinforced concrete (FRC) can be divided in three stages. The first stage is the "stable micro-cracking stage". The second stage is the growth of micro-cracks and development of macro-cracks. The micro-crack growth continues up to a saturation level which depends on the fibre volume content. Finally there is the rapid expansion of the macro-cracks followed by macroscopic fracture [16-20]. 
In the present study, steel FRC beams were subjected to four-point bending with concurrent recording of the AE activity. The maximum load and toughness were measured as a function of the fibre content. Additionally, the cracking mode was related with the fiber content and damage accumulation during the experiment. The interrelation of the measured AE activity with mechanical properties such as the toughness of the fibre reinforced concrete was also studied.

\section{Experimental details.}

The specimens employed for this study were of prism shape. The concrete mix used is typical for shotcrete applications. Details can be found in Table 1. The steel fibres were of wavy shape and three different volume contents were used, namely $0.5 \%, 1 \%$ and $1.5 \%$. For reference, a mixture of plain concrete was also produced. For each of the four mixtures, three specimens were tested in bending with concurrent AE monitoring.

The four-point bending experiments for the determination of the specimen toughness were performed according to the ASTM C1609/C 1609M-05 standard. As shown in Fig. 1, the bottom and top spans were $300 \mathrm{~mm}$ and $100 \mathrm{~mm}$, respectively. The displacement rate was $0.08 \mathrm{~mm} / \mathrm{min}$. More experimental details can be found in [21].

For the purpose of the AE monitoring, two AE sensors of resonance at $150 \mathrm{kHz}$ (R15, Physical Acoustics Corp., PAC) were attached to the bottom side of the beams at a $50 \mathrm{~mm}$ distance from either side of the mid-span (Fig. 1). The use of one or two sensors is typical for monitoring the $\mathrm{AE}$ hit rate and other major parameters in laboratory conditions [16-18,22,23] where event location is not attempted. The pre-amplifier gain was set to $40 \mathrm{~dB}$. After performing a pilot test, the threshold was also set to $40 \mathrm{~dB}$ in order to avoid the possibility of electronic/environmental noise. The signals were recorded in a two-channel monitoring board PCI-2, PAC. AE hits (including waveforms) were recorded with a sampling rate of $5 \mathrm{MHz}$. 


\section{Mechanical behavior}

It is well known that fibres increase the specimen toughness and the results of this study are no exception. Typical load-deflection curves of FRC specimens are depicted in Fig. 2. As expected, the load-displacement curve is linear up to the maximum load for all specimens. Plain concrete also exhibits a linear load displacement curve and fails catastrophically after the maximum load is reached (the curve is omitted from the diagram, as it coincides with the linear part of other curves). The specimens with $1.5 \%$ of fibres exhibit the highest maximum load. The main differences are observed in the post-peak behavior. Plain concrete does not absorb any energy after the maximum load is reached. On the other hand, FRC specimens, exhibit a sudden drop of load after the initial fracture but continue to absorb energy while the load gradually decreases towards the end of the test. As can be seen in Table 2, the increase of fibre content improved the material's toughness which is shown by the area under the load-deflection curves (Fig. 2).

In Fig. 3(a) the main crack of a plain concrete specimen after failure is depicted. The specimen fails with the crack initiating from the bottom surface, which is under tensile load. The crack propagates towards the top, splitting the specimen in two parts. On the other hand, FRC does not break in two parts even after final failure. As can be seen in Fig. 3(b) the main crack is accompanied by smaller cracks. The fracture energy is distributed in a larger volume of material increasing the width of the FPZ. This leads to higher maximum loads for the FRC and higher toughness, i.e. increased area under the load-deflection curves (Fig. 2). The same effect has been reported for large aggregates which had a similar effect on the FPZ [24]. In Fig. 3(c) a crack bifurcation is depicted for a fibre reinforced specimen. It is obvious that the crack changes direction as it propagates to the top. This change of direction will be discussed along with the AE data in the next sections. 


\section{AE results}

\subsection{Total AE hit activity}

In Fig. 4(a) and (b), the cumulative AE hits and the load versus time are depicted, for typical cases of $1.5 \%$ fibre concrete and plain concrete, respectively. In the case of the FRC, at approximately $70 \%$ of the maximum load, an increase in the AE hits is recorded. The hit rate reaches a peak at the moment of macroscopical fracture. The total number of hits is typically 3000 - 4000 (see Fig 4(a)). On the other hand, in the case of the plain concrete specimens (Fig. 4(b)), a notably smaller number of hits are recorded. As can be seen from the figure, the unreinforced concrete specimen fails catastrophically immediately after peak load is reached.

The total AE activity for all fibre contents is shown in Fig. 5(a). Each point is the average of the total number of hits acquired for the whole duration of the three experiments of each content. There is an almost linear relation between the number of hits and the fibre content. This is reasonable because each fiber pull-out event is a potential AE hit and the pull-out events increase with the fiber volume content.

For practical reasons, correlations between mechanical properties and non destructive testing parameters are highly desirable since mechanical measurements are not always feasible. In this case, the toughness of the specimens is correlated through an exponential curve to the number of cumulative AE hits (Fig. 5(b)). Such a metric could be studied for cases where other methods are not directly applicable.

\subsection{Fracture mode}

The shape of the AE waveforms is reported to be characteristic of the fracture mode (Fig. 6(a) and (b)). Shear events are characterized by longer rise time and usually higher amplitude than 
tensile events $[8,25]$. This is examined by the RA value which is defined as the ratio of the Rise time (expressed in $\mu$ s) to the waveform Amplitude (expressed in Volts) $[25,26]$. It has been shown that lower RA values, indicate more tensile nature of fracture events $[8,14]$.

Another parameter that has been used for the characterization of the cracking mode is the average frequency. It is defined as the number of threshold crossings (counts) divided by the duration of the signal, see Fig. 6(b) and is expressed in kHz. The shift from higher to lower values indicates the shift of the cracking mode from tensile to shear $[25,26]$. Classification of cracks based on these two indices, has been reported to produce results less dependent on the type of sensors [25].

In the present case, the cracking process starts at the bottom surface for all specimens due to the tension. However, shear stresses develop on the horizontal plane and especially on the neutral axis. These stresses are connected to the change of direction of the crack in FRC and the resulting increase of the RA value. The change of the RA value may be either expressed as a mean value for each fibre content or as a dynamic change throughout the loading process.

In Fig. 7(a), the average RA values are depicted for different fibre contents for the whole duration of the experiments. Plain concrete specimens exhibit the lowest RA for all the AE hits recorded throughout the experiments. The inclusion of fibres, even in just $0.5 \%$ per volume leads to considerable increase of RA which is associated to the change of the failure mode from tensile to shear. Further increase in fibre volume content has a small influence on RA since a plateau is reached.

Figures 7(b)-7(d) depict the change of RA vs. time for all three specimens for $1.5 \%$ fibre content. Each point of the curves corresponds to the moving average of RA for 50 consecutive hits in order to reduce scatter. The load history is also depicted in arbitrary scale, to show the main 
failure moment for each specimen. As the deflection of the specimen increases and the fracture proceeds, RA is gradually increasing until the end of the experiment. As can be seen in the same figures, the average frequency is decreasing throughout the experiments. The RA shift to lower values indicates that although the cracks are initiated by tension, gradually shear stresses dominate the failure process. This has also been recently reported for vinyl-fibre concrete [27]. Similar behavior has been reported in corrosion cracking of concrete where crack initiation was of the tensile mode (I), while as the crack length increased the shear mode (II) became more active [28]. As seen in Table 2, the increase in fibre content, which activates the shear mode, is closely connected to the increased fracture toughness of FRC. Therefore, the specimens do not break with a single vertical crack. The crack splits in different smaller cracks, increasing the volume of the material involved in the fracture process. According to the experimental findings and the above discussion, RA values of approximately $2000 \mu \mathrm{s} / \mathrm{V}$ suggest active tensile mode, while RA values above $4000 \mu \mathrm{s} / \mathrm{V}$ indicate shear mode. The same shift from tensile to shear is expressed by the drop of the average frequency from approx. $60 \mathrm{kHz}$ to $35 \mathrm{kHz}$. It should be mentioned, that use of more sensors will enable the characterization of the crack location in the specimen volume and consequently the determination of the actual width of the fracture process zone $[24,29]$ which is directly related to the toughness of the material.

\section{Conclusions}

In the present study the influence of steel fibres in the behavior of concrete under bending is discussed. Increased fibre content results in the increase of the maximum load and the fracture toughness of the material. At the same time, the amount of AE activity is proportional to the fibre content and the measured toughness. Analysis of AE parameters reveals that the tensile mode of fracture is dominant for plain concrete. The mode of fracture is changing to shear as the fibre content increases. This demonstrates the reinforcing effect of the fibres against the weak tensile 
nature of concrete. The study of AE indices implies that the mode of fracture changes during the experiment from tensile (initial stage) to shear (final fracture). This is macroscopically shown by the crack splitting and deflection from parallel to perpendicular direction relatively to the loading axis and the concurrent increase of the fracture process zone with increasing fibre content.

As was shown, the acoustic emission technique can be employed for the identification of the fracture mode. The identification of the failure mode is of primary importance as it provides insight for a more suitable design of the reinforcement, in order to withstand the specific stresses. Additionally, as shear cracking follows tensile cracking, crack classification using suitable AE descriptors can assist the evaluation of the severity of the condition.

The use of the aforementioned methodology to classify the fracture mode of FRC can also be employed for different types of reinforcement in terms of fibre shape, material and volume content, in order to increase the reinforcing efficiency for optimal structural performance. Furthermore, source location of the AE events via the use of more sensors can experimentally verify the increase of the fracture process zone with increasing reinforcement efficiency. 


\section{References}

1 Stahli P, van Mier JGM. Manufacturing, fibre anisotropy and fracture of hybrid fibre concrete. Engineering Fracture Mechanics 2007;74:223-242

2 Mobasher B, Stang H, Shah SP. Microcracking in Fibre Reinforced Concrete. Cement and Concrete Research 1990; 20:665-676.

3 Sivakuram A, Sathanam M. Mechanical properties of high strength concrete reinforced with metallic and non-metallic fibres. Cement and Concrete Composites 2007; 29:603608.

4 Fischer G, Li VC. Effect of fibre reinforcement on the response of structural members. Engineering Fracture Mechanics 2007; 74:258-272

5 Washer G, Fuchs P, Graybeal BA, Hartman JL. Ultrasonic testing of reactive powder concrete. IEEE Transactions on Ultrasonics, Ferroelectrics, and Frequency Control 2004; 51(2):193-201

6 Shiotani T, Aggelis DG. Evaluation of repair effect for deteriorated concrete piers of intake dam using AE activity. Journal of Acoustic Emission 2007; 25:69-79

7 Shiotani T, Aggelis DG, Makishima O. Global monitoring of concrete bridge using acoustic emission. Journal of Acoustic Emission 2007; 25:308-315

8 Shiotani T, Ohtsu M and Ikeda K. Detection and evaluation of AE waves due to rock deformation. Construction and Building Materials 2001; 15(5-6):235-246

9 Aggelis DG, Shiotani T, Momoki S, Terazawa M. Acoustic emission of full scale concrete beams for evaluation of joint effect, Advances in Acoustic Emission - 2007, (ed. K. Ono), pp.390-395 (Proc. $6^{\text {th }}$ International Conference on Acoustic Emission, Lake Tahoe, Nevada, USA, October 29th-November 2nd, 2007)

10 Triantafillou, TC. and Papanikolaou, CG. Shear strengthening of reinforced concrete members with textile reinforced mortar (TRM) jackets. Materials and Structures 2006; 
39(1):93-103

11 Golaski L, Swit G, Kalicka M, Ono K. Acoustic emission behavior of prestressed concrete girder during proof loading. Journal of Acoustic Emission 2006; 24:187-196

12 Shah HR, Weiss J. Quantifying shrinkage cracking in fibre reinforced concrete using the ring test. Materials and Structures 2006; 39(9):887-899

13 Shigeishi M, Ohtsu M. Identification of acoustic emission sources by using SiGMA-2D moment tensor analysis. Acoustic Emission: Standards and Technology Update, ASTM STP 1353, Vahaviolos SJ, ed. American Society for Testing and Materials 1999;175-188

14 Ohtsu M, Okamoto T, Yuyama S. Moment tensor analysis of AE for cracking mechanisms in concrete. ACI Structural J 1998; 95(2):87-95

15 Kumar A, Gupta AP. Acoustic emission in fibre reinforced concrete. Experimental Mechanics 1996; 36(3):258-261

$16 \mathrm{Wu} \mathrm{K}$, Chen B, Yao W. Study on the AE characteristics of the fracture process of mortar, concrete and steel-fibre-reinforced concrete beams. Cement and Concrete Research 2000;30:1495-1500

17 Chen B, Liu J. Damage in carbon fibre-reinforced concrete, monitored by both electrical resistance measurement and acoustic emission analysis, Construction and Building Materials 2008;22:2196-2201.

$18 \mathrm{Wu} \mathrm{K}$, Chen B, Yao W. Study of the influence of aggregate size distribution on the mechanical properties of concrete by acoustic emission technique. Cement and Concrete Research 2001;31:919-923

19 Kim B, Weiss WJ. Using acoustic emission to quantify damage in restrained fibrereinforced cement mortars. Cement and Concrete Research 2003;33: 207-214

20 Weiler B, Grosse CU, Reinhardt HW. Quantitative acoustic emission used for the evaluation of fracture mechanisms in steel fibre reinforced concrete, Proceedings of the 
$22^{\text {nd }}$ European Conference on Acoustic Emission Testing, Aberdeen, Scotland, $1996 ; 119-124$

21 Soulioti D, Matikas TE. Mechanical properties of fibre-reinforced concrete with variable shape and content of steel fibres, Proc. of the $1^{\text {st }}$ Conference on Structural Materials and Components, 2008, vol. C, pp.1287-1298, 21-23 May, Athens, Greece. (In Greek)

22 Ohtsu M., Watanabe H. Quantitative damage estimation of concrete by acoustic emission. Construction and Building Materials 2001;15: 217-224.

23 Ohtsu M., Suzuki T. Quantitative damage evaluation of structural concrete by a compression test based on AE rate process analysis. Construction and Building Materials 2004;18: 197-202.

24 Mihashi H, Nomura N, Niiseki S. Influence of aggregate size on fracture process zone of concrete detected with three dimensional acoustic emission technique. Cement and Concrete Research 1991;21:737-744

25 Ohtsu M, Tomoda Y. Phenomenological model of corrosion process in reinforced concrete identified by acoustic emission. ACI Materials Journal 2007;105(2):194-200.

26 RILEM TC212-ACD: “Acoustic Emission and Related NDE Techniques for Crack Detection and Damage Evaluation in Concrete" - 2008 Recommendation 3.

27 Aggelis DG, Momoki S, Shiotani T, Hirama A. "Acoustic emission behavior of twolayered, reinforced concrete slabs under bending”. On Site Assessment of Concrete, Masonry and Timber Structures SACoMaTiS 2008, Proc. Of the First RILEM Symposium, Lake Como, Italy, 1-2 September 2008.Vol. 1, pp. 25-34.

28 Farid Uddin AKM, Numata K, Shimasaki J, Shigeishi M, Ohtsu M. Mechanisms of crack propagation due to corrosion of reinforcement in concrete by AE-SiGMA and BEM. Construction and Building Materials 2004; 18:181-188

29 Grosse CU, Finck F. Quantitative evaluation of fracture processes in concrete using 
signal-based acoustic emission techniques. Cement and Concrete Composites 2006;28:330-336

Table 1. Specimen and fiber characteristics

Specimen size $(\mathrm{mm}) \quad 400 \times 100 \times 100$

Water to cement (by mass) $\quad 0.5$

Aggregate to cement (by mass) 3.6

Fine to coarse aggregates (by mass) $\quad 77 / 23$

Max. aggregate size (mm) 10

Fiber length (mm) 25

Fiber diameter $(\mathrm{mm}) \quad 0.75$

Table 2. Mechanical properties for different fibre contents

Fibre Content

$(\%)$

0

0.5

1

1.5
Maximum load

$(\mathrm{kN})$

Flexural

toughness, $\mathrm{T}_{100,2}{ }^{*}$

(J)

14.9

13.2

15.8

19.9
7.0

15.3

17.3

*The subscripts denote the specimen thickness $(100 \mathrm{~mm})$ and the maximum center deflection of the specimen (2 mm) according to ASTM C 1609/C 1609M-05. 
Figure captions

Fig. 1 Experimental setup.

Fig. 2 Load vs. deflection curves for specimens with different fibre contents.

Fig. 3 Cracks obtained for plain concrete (a), concrete with $1.5 \%$ fibres (b), (c)

Fig. 4 Load and AE history for specimen with (a) 1.5\% fibres, (b) $0 \%$ fibres, (the hit axis is in logarithmic scale)

Fig. 5 (a) Total AE hits vs. fibre content, (b) toughness vs. AE hits for different fibre contents.

Fig. 6 (a) Typical waveforms of (a) tensile, (b) shear event. A is the amplitude and RT the Rise time (time between the onset and the point of maximum amplitude) of the waveforms.

Fig. 7 (a) Average RA value vs. fibre content, (b)-(d) moving average of RA and average frequency for the three specimens with $1.5 \%$ of fibres. 




Fig. 1. Experimental setup.

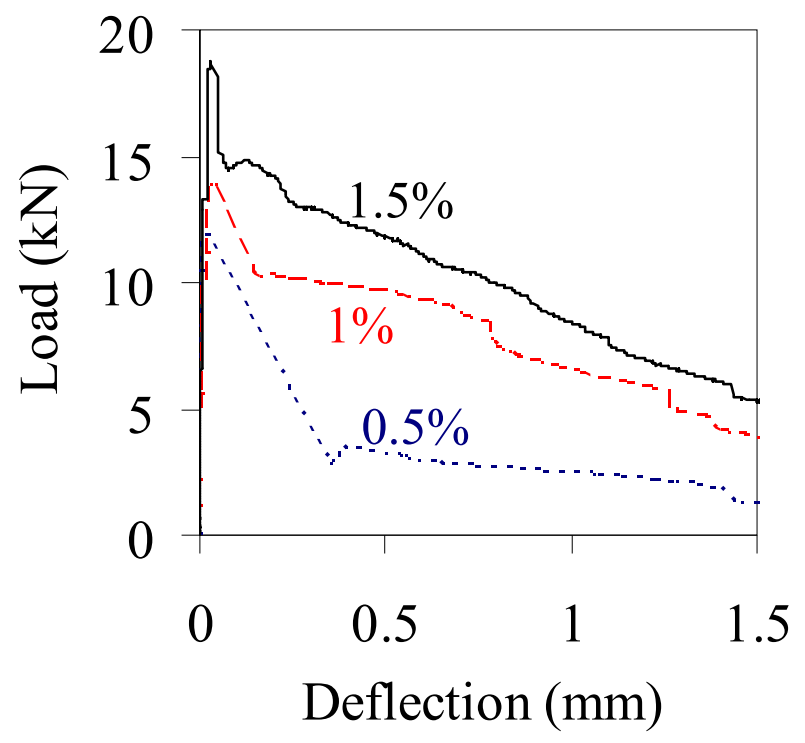

Fig. 2 Load vs. deflection curves for specimens with different fibre contents. 


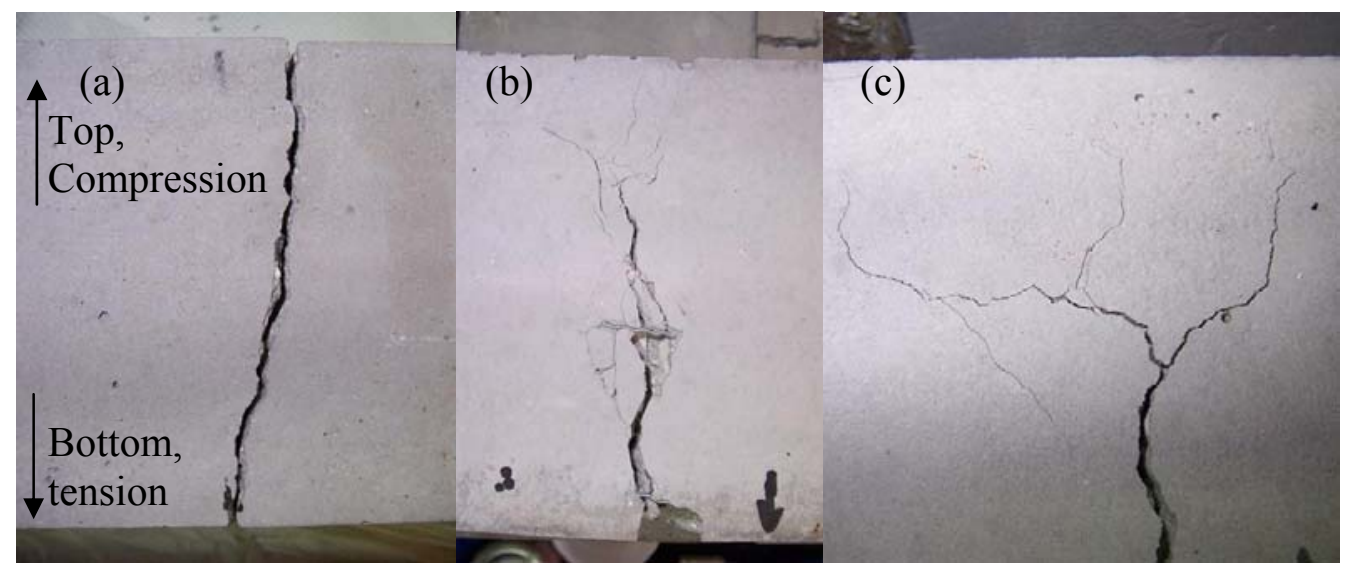

Figure 3. Cracks obtained for plain concrete (a), concrete with $1.5 \%$ fibres (b), (c).

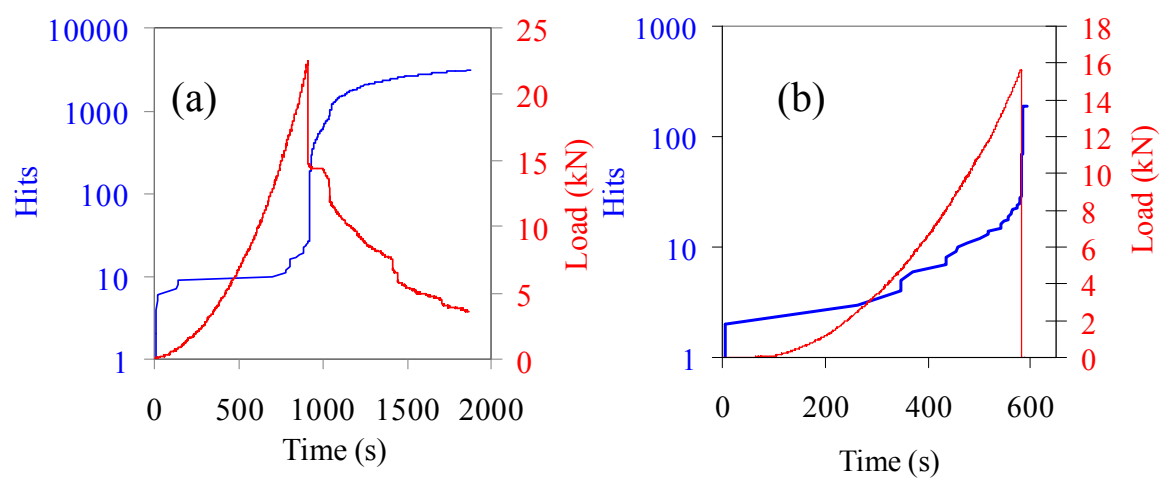

Figure 4. Load and AE history for specimen with (a) 1.5\% fibres, (b) $0 \%$ fibres, (the hit axis is in logarithmic scale). 

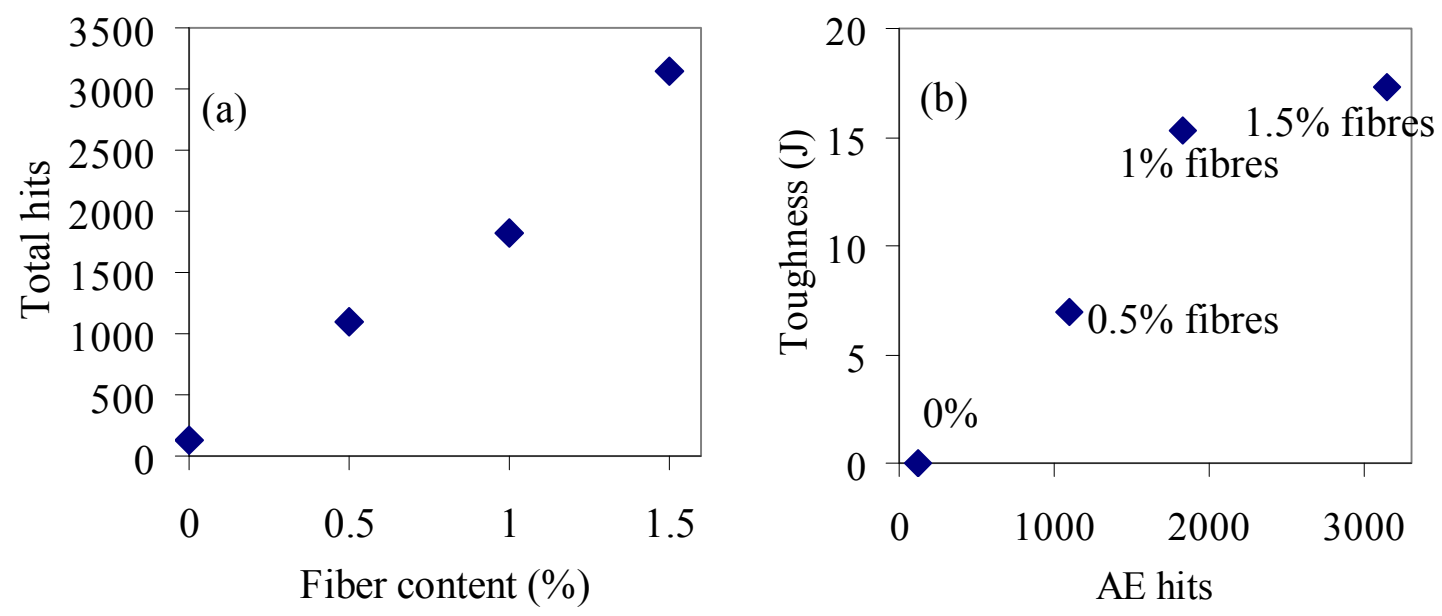

Fig. 5. (a) Total AE hits vs. fibre content, (b) toughness vs. AE hits for different fibre contents.

(a)

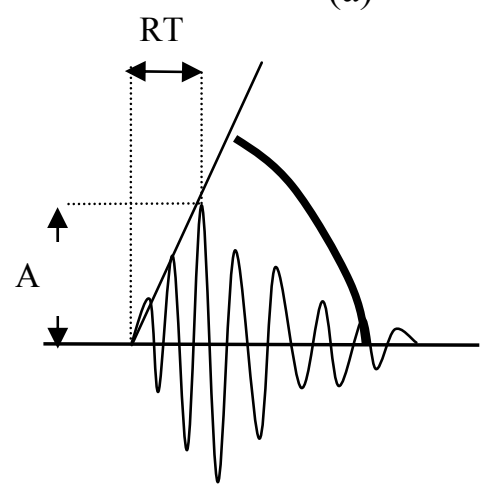

(b)

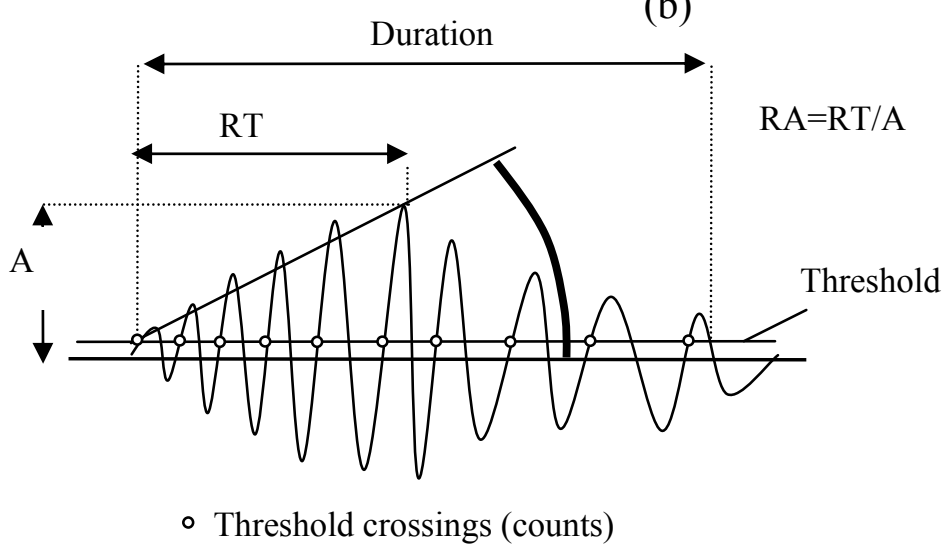

Fig. 6. (a) Typical waveforms of (a) tensile, (b) shear event. A is the amplitude and RT the Rise time (time between the onset and the point of maximum amplitude) of the waveforms. 

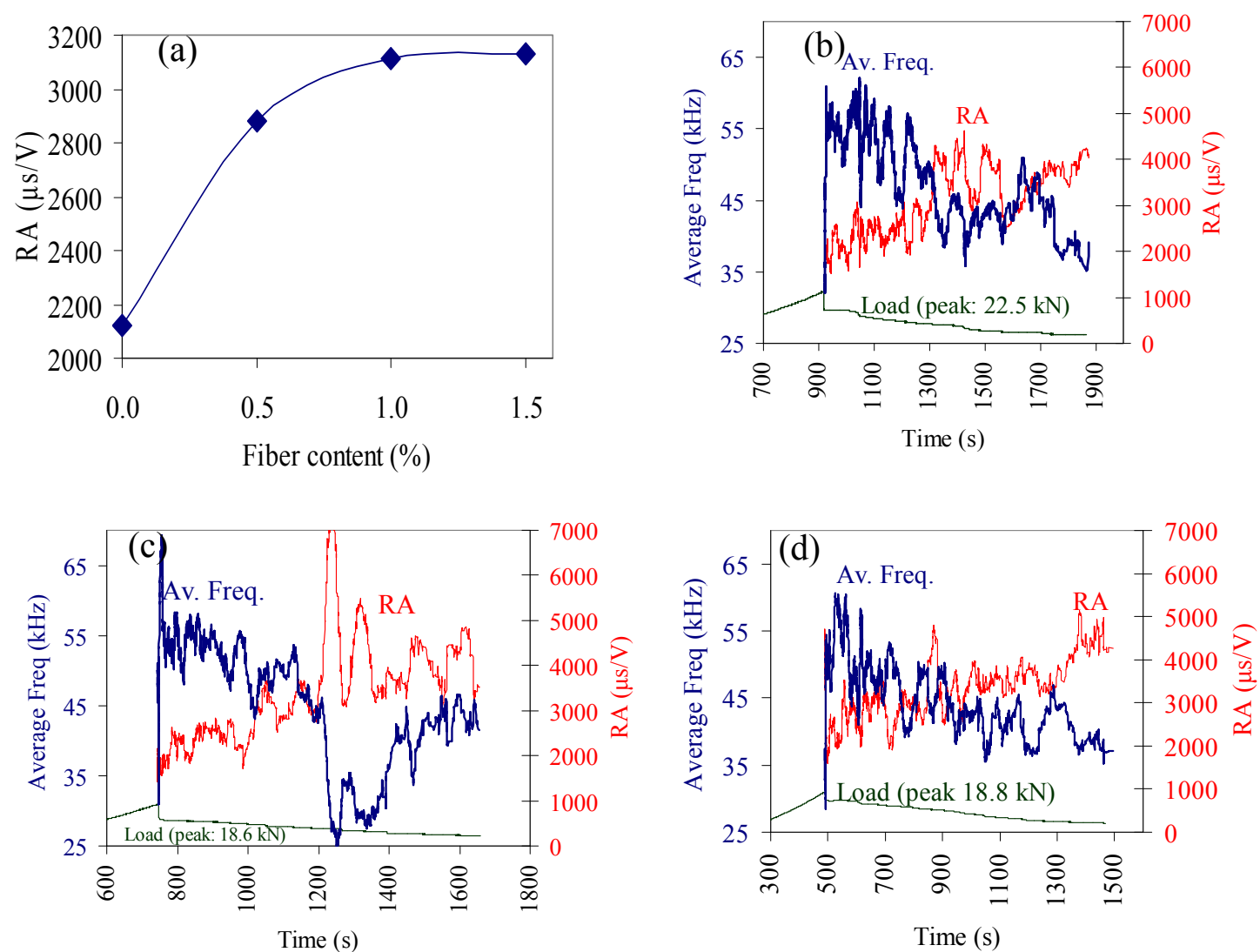

Figure 7. (a) Average RA value vs. fibre content, (b)-(d) moving average of RA and average frequency for the three specimens with $1.5 \%$ of fibres. 